\title{
Informing extension project design: the right tool for the job
}

\author{
T.A. PAYNE ${ }^{1}$, J.A. TURNER ${ }^{1}$, K. RIJSWIJK ${ }^{1,2}$, A.K. McDERMOTT ${ }^{3}$ and R.D.N. WAKELIN ${ }^{4}$ \\ ${ }^{1}$ AgResearch, Private Bag 3123, Hamilton 3240, New Zealand \\ ${ }^{2}$ Knowledge, Technology and Innovation Group, Wageningen University, Wageningen, The Netherlands \\ ${ }^{3}$ ANZCO Food Ltd, PO Box 39-186, Harewood, Christchurch 8053, New Zealand \\ ${ }^{4}$ Beef + Lamb New Zealand, 154 Featherston Street, Wellington 6140, New Zealand
}

tracy.nelson@agresearch.co.nz

\begin{abstract}
Extension successfully creates change when projects are designed to fit the issue, opportunity, or technology to be implemented, the potential users, and the influences external to the farm team. To better understand when and why different approaches to extension succeed this study developed a typology of nine extension approaches. The nine approaches provide a framework to identify the right extension approaches that will drive sustainable productivity improvements for higher onfarm profitability. Factors that need to be understood when deciding which of the extension approaches is best suited to a particular circumstance are: farmers' awareness of the problem, problem complexity, benefits desired by farmers, compatibility of the new technology with existing farm management, and the ability of the farm team to implement the technology. This paper outlines the 9 extension approaches, and the criteria and process for choosing the appropriate approach for the circumstances.
\end{abstract}

Keywords: extension approaches, technology transfer, co-development

\section{Key messages:}

- Project teams need to identify the characteristics of the issue and the technologies that address the issue when designing extension projects

- When designing extension projects, project teams need to consider who is part of the extension project (e.g. farmers, farm advisors, researchers), and the roles they each play in the project

- Extension projects are more likely to lead to technology uptake when they are designed and resourced (including time and project team capabilities) to match the characteristics of the problem being addressed, technology being implemented and the potential users of the technology.

\section{Introduction}

The ability of agricultural extension to deliver uptake of new agricultural technologies and practices has been influenced by changes in the extension service and the increasing complexity of agricultural challenges. Until the 1980s New Zealand's agricultural extension services were delivered as a public good through the then Ministry of Agriculture and Fisheries. From the mid-1980s agricultural extension was commercialised and then privatised (Botha et al. 2006; Morriss et al. 2006). This contributed to the fragmentation of activities supporting uptake of technologies and wider innovation among industry, industry good bodies, rural advisors, local government, the Crown Research Institutes (CRIs), and research funding mechanisms (Botha et al. 2006; Morriss et al. 2006; McEntee 2010; MPI 2012). At the same time the types of challenges facing New Zealand and global agriculture are now more complex; involving environmental and social outcomes in addition to economic and production outcomes, multiple sectors, and off-farm and well as on-farm change (Spielman et al. 2009; Schut et al. 2014a; Schut et al. 2014b). Examples are nutrient management and animal welfare requirements. Together this fragmentation and complexity has reduced the effectiveness of traditional linear extension approaches from expert to farmer (Marsh \& Pannell 2000) and led to development of new extension approaches such as farm systems, Farmer First and codevelopment (Röling 2009).

To better understand when and why different approaches to extension succeed, this study developed a typology of nine extension approaches. Factors that need to be understood when deciding which of the extension approaches is best suited to a particular circumstance are: farmer awareness of the problem, problem complexity, benefits desired by farmers, compatibility of the new technology with existing farm management, and the ability of the farm team to implement the technology. The ADOPT tool was used as a starting point for developing the typology. While this is a useful tool to predict the rate and level of adoption and factors which influence adoption (Kuehne et al. 2011) ADOPT does not provide insight into what extension approach to use in different circumstances.

This paper first presents the methods used to understand when and why different approaches to extension are successful. This is followed by a description of the typology of extension approaches identified, including under what circumstances they are likely to be successful. 


\section{Methods}

\section{Framework development}

Potential factors that influence extension success were identified from a review of studies of farmer decision making, technology uptake and practice change (e.g. Pannell et al. 2006; Vanclay 2004; Kuehne et al. 2011), technology transfer (e.g. Kline \& Rosenberg 1986), extension (e.g. Benson \& Jafry 2013) and agricultural innovation systems (e.g. Hall et al. 2006; Klerkx et al. 2012). These factors cover aspects of extension design and the context in which extension is applied e.g. characteristics of the issue.

A framework was then developed to identify which of these factors influence extension success and how. Aspects of the extension design covered in the framework include: drivers of practice change addressed by the approach; who is part of the extension project; role of these participants; sources of knowledge. The framework covered aspects of the context in which the extension project is applied including: awareness of the issue being addressed; trialability and relative advantage of the new technology compared with existing farm management; farm system characteristics; and user population characteristics (Turner et al. 2014).

\section{Typology development}

To develop a typology of extension approaches a bibliography of 640 studies of extension projects from the extension and agricultural innovation systems literature was created. Fifty studies were selected for in-depth analysis based on their relevance to the New Zealand red meat sector, inclusion of measures of successful extension, and the extent that they covered as many of the factors as possible from the framework.

The chosen studies were coded to identify the extension design and contextual factors commonly associated with successful projects. This process of coding involved tagging sections of text to the factors in the framework. From this, extension design and contextual factors were identified that were most commonly associated with successful extension projects. This enabled the list of design and contextual factors identified in the framework to be reduced to priority factors associated with successful projects. A typology was created based on differences in the design of the extension approach and circumstances in which the approaches were applied.

\section{Results and Discussion}

A typology of nine extension approaches were identified based on differences in the design of the extension approach and the circumstances in which the approaches had been successfully applied. This section describes each of the extension approaches, gives an overview of the related extension activities (Table
1), and how to identify the extension approach that is appropriate for their circumstances.

\section{Technology push}

The technology push approach is used to raise farmer awareness of technologies that address non-complex issues with beneficial and observable impacts on-farm. An example is the loss of clover in pastures due to clover root weevil (Phillips et al. 2007). The technologies are compatible with existing farm management, and can easily be tested providing observable benefits desired by farmers. Farmers have the ability to implement the technology and are not hindered by factors external to the farm from adopting the technology. Technology push utilises extension agents and farm advisors as the main providers of knowledge to technology users across a range of locations, using articles in farming media, field days and demonstration trials (Table 1).

\section{Marketing technologies}

Marketing technologies achieves uptake of technologies by stimulating farmer demand through multiple co-ordinated channels of advice (Table 1). An example is the Prime Pasture Program which promoted increased and improved pasture renewal practices in Australia (Keys \& Orchard 2000). This approach is used to address non-complex issues that do not have immediately observable impacts, and farmers have a low awareness of the issue. The technologies are compatible with existing farm management, and can easily be tested providing observable benefits, and farmers have the ability to implement the technology.

\section{Transfer of fit-for-purpose technologies}

The transfer of fit-for-purpose technologies approach achieves uptake of new technologies by first understanding farmers' needs and constraints, and using this information to adapt technologies so they are fit-for-purpose and to raise awareness of the issue the technology addresses (Table 1). An example is the adoption of lupin across areas of Western Australia with different farm systems, climatic constraints and markets (Marsh et al. 2000). Technologies developed will be specific to regional farm systems. The approach is used to address non-complex issues that do not have immediately observable impacts on-farm. Farmers have low awareness of the issue the technology addresses. To implement the technologies requires changes to existing farm practices, but the technologies can be tested on part of the farm. The benefits may not be immediately observable.

\section{Farmer-led farm experimentation and extension}

The farmer-led farm experimentation and extension approach achieves uptake of technologies to address 
issues identified by members of the farmer-led extension project. It is user-led and problem-focused. It is used to address non-complex to complex issues that have observable impacts that farmers are aware of. The technologies developed provide observable benefits by addressing farmers' needs. On-farm experimentation and testing (Table 1) is used to develop location specific technologies that are compatible with existing management, farmer ability, and factors external to the farm. An example is the Liebe group of cropping farmers in Western Australia (Gianatti \& Carmody 2007) who formed partnerships with other grower groups, researchers and private industry to carry out research and development activities to increase crop production.

\section{Farmer-led partner farms}

Farmer-led partner farms achieve uptake of farm system-level fit-for-purpose technologies to address problems identified by members of the farmer-led extension project. It is user-led and focused on solving complex problems influencing the whole farm. An example is the Cicerone project in Australia, which ran three farmlet studies evaluating farm system-level practices for increasing sheep and beef production and profitability (Coventry et al. 2013; Edwards et al. 2013; Scott et al. 2013). Technologies developed are matched to specific regional farm systems, climate and markets. This approach is used to address complex issues that have observable impacts that farmers are aware of. The practices developed will address farmers' needs, but require intensive and robust data collection to demonstrate benefits. The system-wide farm management changes have limited compatibility with existing management, and are difficult to test and demonstrate on part of a farm. It focuses on developing, testing and demonstrating technologies by farmers and researchers on partner farms (Table 1). Partner farms are intensive research-extension-farm relationships in which all involved equally contribute to development of knowledge (Crawford et al. 2007).

\section{Science-led experimental farms}

This approach achieves uptake of technologies jointly developed by researchers and farmers. Technologies developed will be matched to regional farm systems, climate and markets. It is used to address non-complex to complex issues that farmers may not be aware of, in part because the issue does not have readily observable impacts. The technologies developed will seek to address farmers' needs, but require robust testing and data collection in experimental farm trials (Table 1) to demonstrate potential benefits and ensure technologies are fit-for-purpose as they may be difficult to test on farm and have limited compatibility with existing management. An example is the Massey University project on the use of herb pastures for lamb finishing (Sewell et al. 2014). The approach focuses on developing, testing and demonstrating technologies on experimental farms with farmers and scientists.

\section{Co-development with science and farmers}

This approach achieves uptake of technologies to address problems jointly identified by researchers and farmers. It is problem-focused and farmers participate in the development to ensure the technologies are fit-forpurpose. This approach is used to address non-complex to complex issues that farmers have a moderate to high awareness of, in part because the issue has observable impacts on-farm. The technologies developed will address farmers' needs, but require robust testing and data collection in on-farm trials to demonstrate potential benefits, and ensure technologies are fit-for-purpose. The benefits of the technologies are not immediately observable, they may have limited compatibility with existing management, and farmers may feel they lack the ability to implement the technology. The approach focuses on farmers and researchers together developing, testing and demonstrating a collection of technologies on companion farms (Table 1). An example is the development of location specific technologies for sustainable rice production in the Philippines (Pascaul \& Bumatay 2012). This project implemented demonstration and learning fields and weekly farmer field schools. It involved two groups of farmers, farmer partners who managed the technology demonstration farm and participating farmers who cultivated fields around the demonstration fields and maintained farmers' learning fields.

\section{Co-development with farmers, advisors and science}

This approach achieves uptake of technologies to address problems jointly identified by farmers, farm advisors and researchers. The approach is problemfocused with participation of farm advisors necessary to implement fit-for-purpose technologies with farmers. Farm advisors are integral to the successful implementation of technologies, as farmers alone cannot implement the technologies. This approach is used to address complex issues that farmers have a modest awareness of. The technologies are complex, they do not have immediately observable benefits, are difficult to test on-farm and have limited compatibility with existing technologies. The approach focuses on farmers, extensions agents and researchers together developing, testing and demonstrating a collection of fit-for-purpose technologies (Table 1). An example is the use of crop process models for precision cropping in northeast Australia (FARMSCAPE; Carberry et al. 2002). FARMSCAPE looked at whether farmers valued 
simulation as a decision support tool, and whether this could be delivered cost-effectively by advisors. Farmer group engagement, on-farm trials, soil characterisation, monitoring of crops, soils and climate, and sessions to apply the crop process model were used by advisors to deliver information to dryland farmers.

\section{Co-development with supply chain participants}

This approach achieves uptake of technologies to address problems jointly identified by farmers, farm advisors, processors, consumers and researchers. The approach is problem-focused with participation of many in the supply chain who are needed to implement workable solutions. It includes people along the whole supply chain who are integral to implementation of the solution and to ensure technologies developed meet the different needs of supply chain participants. The technologies themselves are complex; they may not have immediately observable benefits; and have limited compatibility with existing management for some in the supply chain. The approach focuses on supply chain participants together developing, testing and demonstrating a collection of it-for-purpose technologies (Table 1). An example is the Zespri learning model for adoption of harvesting practices to improve fruit colour (Parminter \& Max 2004). This project involved joint learning among growers, packers, processors and exporters, to co-develop practices from orchard to export, to deliver kiwifruit with improved colour.

\section{How to identify which extension approach to use}

To identify the extension approach that is most likely to achieve the desired levels of practice change (awareness, contemplation, preparation, uptake or maintenance) an online resource has been developed [www. redmeatextension.co.nz] which guides users through identification of the best suited extension approach. This resource also includes additional information on the extension approaches and activities. An important consideration in the choice of extension approach is the capability of the extension team, budget and timeframe. These are important constraints that will influence what extension approach can be undertaken, and hence what degree of practice change or technology uptake can feasibly be achieved.

In practice, individual extension projects will include more than one extension approach to achieve uptake as farmers' awareness of the issue and capabilities to implement technologies improve, and evidence of the benefits of the technology are observed. For example, a transfer of fit-for-purpose practices approach may be used to understand farmer needs and constraints related to a technology, issue or opportunity. This information can then be used to inform the design of a farmer-

Table 1 Activities used by each extension approach.

\begin{tabular}{ll}
\hline Extension Approach & Extension Activities \\
\hline Technology push & Mail outs; advertising and articles in farming media; field days; demonstration trials \\
\hline Marketing technologies & $\begin{array}{l}\text { Mail outs; advertising and articles in farming media; field days; demonstration trials; one-on- } \\
\text { one advice from retailers, rural advisors and contractors }\end{array}$ \\
\hline Transfer of fit-for-purpose & $\begin{array}{l}\text { Surveys; interviews \& focus groups with farmers; farmer discussion groups at demonstration } \\
\text { trials; extension agents one-on-one discussions with farmers; advertising and articles in } \\
\text { farming media; field days; advice from retailers, rural advisors and contractors (supported by } \\
\text { training of these knowledge providers) }\end{array}$ \\
\hline
\end{tabular}

Farmer-led farm experimentation and extension

Farmer-led partner farms

Science-led experimental farms

Co-development with science and farmers

Demonstration and focus farms; farm trials; farmer-to-farmer discussion groups, including invited providers of knowledge, farm field days, newsletters, visits to other farmer-led groups

Partner farms; farmlet studies and trials; learning groups (including farmers, rural advisors and researchers); research projects; farm field days, newsletters; conference presentations

Research trials; learning groups (including farmers, rural advisors and researchers); research projects; farm field days; newsletters; and conference presentations

Farm trials; side-by-side comparisons of alternative practices; learning groups; including farmers and researchers; farmer training; farm field days; newsletters; visits to other extension projects

Co-development with farmers, advisors and science

Farm trials; rural advisor trials; learning groups; including farmers, rural advisors and researchers; farmer-rural advisor training; researchers-rural advisor exchanges; farm field days; one-on-one advice; newsletters; visits to other extension projects

Co-development with supply chain participants
Farm, processing, rural advisor, consumer trials; learning groups; incl. supply chain participants; training for supply chain participants; farm and processor field days; one-on-one advice; visits to other extension projects. 
led partner farms approach. This can be followed by a technology push approach to extend the technology beyond the immediate participants in the extension project, having demonstrated the benefits of new practices.

\section{Conclusions}

The nine extension approaches provide a typology to choose the approach that can help extension projects drive sustainable productivity improvements to deliver higher on-farm profitability. Extension projects are more likely to achieve technology uptake when they are designed to match the characteristics of the problem being addressed, technology being implemented and the potential users of the technology. The nine extension approaches differ in key aspects, which need to be designed to fit the circumstances of the opportunity, including information sources and the role of the farm team, project team, farm advisors and scientists as sources of knowledge and setting priorities for the project. Key factors that need to be understood when deciding which extension approach is best suited are: farmers' awareness of the problem, problem complexity, benefits desired by farmers, compatibility of the new technologies with existing farm management and the ability to implement the technology. To achieve technology uptake, extension needs to be designed to fit the problem, opportunity, or technology to be implemented, the potential users, and the influences external to the farm team. To determine the best extension approach for the circumstances, information about the particular opportunity and technologies to realise the opportunity need to be gathered from farmers and farm advisors. However, it is important to realistically match the extension approach to available resources. The right approach may not be possible to achieve the desired level of uptake due to limited resources. This may require a change to the stage of practice change sort, for example instead of 'uptake' the project instead may focus on 'awareness'.

\section{ACKNOWLEDGEMENTS}

The authors wish to thank the Red Meat Profit Partnership for funding this research. The study benefited from the input of a number of people including David Stevens, Denise Bewsell, Neels Botha and Bruce Small, AgResearch. The feedback from extension academics and practitioners on the framework developed ensured its completeness.

\section{REFERENCES}

Benson, A.; Jafry, T. 2013. The state of agricultural extension: an overview and new caveats for the future. Journal of Agricultural Education and Extension 19: 381-393.
Botha, N.; Coutts, J.; Roth, H. 2006. The role of agricultural consultants in the New Zealand Research, Development and Extension system. Paper presented at the New Zealand Agricultural and Resource Economics Society conference, Nelson.

Carberry, P.S.; Hochman, Z.; McCown, R.L.; Dalgliesh, N.P.; Foale, M.A.; Poulton, P.L.; Hargreaves, J.N.G.; Hargreaves, D.M.G.; Cawthray, S.; Hillcoar, N.; Robertson, M.J. 2002. The FARMSCAPE approach to decision support: Farmers', advisers', researchers' monitoring, simulation, communication and performance evaluation. Agricultural Systems 74: 141-177.

Coutts, J.; Roberts, K. 2003. Extension models and best practice in extension. Invited paper, APEN Forum, Hobart.

Coventry, T.; Sutherland, H.; Waters, M.; Dutton, P.; Gream, B.; Croft, R.; Hall, E.; Paul, D.R.; Edwards, C.; Marchant, R.; Smith, P.; Scott, J.M.; Gaden, C.; Hoad, J. 2013. Reflections on the concept, conduct and findings of the producer-led Cicerone Project. Animal Production Science 53: 856-868.

Crawford, A.; Nettle, R.; Paine, M.; Kabore, C. 2007. Farms and learning partnerships in farming systems projects: A response to the challenges of complexity in agricultural innovation. Journal of Agricultural Education and Extension 13: 191-207.

Eastwood, C.R.; Chapman, D.F.; Paine, M.S. 2012. Networks of practice for co-construction of agricultural decision support systems: Case studies of precision dairy farms in Australia. Agricultural Systems 108: 10-18.

Edwards, C.; Gaden, C; Marchant, R.; Coventry, T.; Dutton, P.; Scott, J.M. 2013. Delivering extension and adult learning outcomes from the Cicerone project by 'comparing, measuring, learning and adapting'. Animal Production Science 53: 827840.

Gianatti, T.M.; Carmody, P. 2007. The use of networks to improve information flows between grower groups and researchers. Field Crops Research 104: 165-173.

Hall, A.; Janssen, W.; Pehu, E.; Rajalahti. R. 2006 Enhancing agricultural innovation: how to go beyond the strengthening of research systems. World Bank, Washington, D.C.

Keys, M.J.; Orchard, P.W. 2000. The Prime Pasture Program - using marketing concepts to achieve technology transfer. Australian Journal of Experimental Agriculture 40: 541-546.

Klerkx, L.; Mierlo, B.; Leeuwis, C. 2012. Evolution of systems approaches to agricultural innovation: concepts, analysis and interventions. pp. 457-483. In: Farming systems research into the 21st Century. Eds. Darnhofer, I.; Gibbon, D.; Dedieu, B. The New Dynamic. Springer Netherlands. 
Kline, S.J.; Rosenberg, N. 1986. An overview of innovation. The positive sum strategy: harnessing technology for economic growth. National Academy Press, Washington D.C.

Kuehne, R.; Llewellyn, D.; Pannell, R.; Wilkinson, P.; Dolling, P.; Ewing. M. 2011. ADOPT: a tool for predicting adoption of agricultural innovations Australia Agricultural and Resources Economics Society, Melbourne.

Marsh, S.P.; Pannell, D.J.; Lindner R.K. 2000. The impact of agricultural extension on adoption and diffusion of lupins as a new crop in Western Australia. Australian Journal of Experimental Agricultural 40: 571-583.

McEntee, M. 2010. More carrot and less stick: lessons from agricultural extension in New Zealand,. In: $8^{\text {th }}$ World Congress of Participatory Action Research and Action Learning, Melbourne Australia. http:// www.alara.net.au/wc2010/proceedings (Accessed 19th April, 2013)

Ministry for Primary Industries. 2012. Survey of technlogy transfer services to farmers and growers in New Zealand. Report by the Ministry for Primary Industries, Wellington.

Morriss, S.; Massey, C.; Flett, R.; Alpass, F.; Sligo, F. 2006. Mediating technological learning in agricultural innovation systems. Agricultural Systems 89: 26-46.

Pannell, D.J.; Marshall, G.R.; Barr, N.; Curtis, A.; Vanclay, F.; Wilkinson, R. 2006. Understanding and promoting adoption of conservation practices by rural landholders. Australian Journal of Experimental Agriculture 46: 1407-1424.

Parminter, T.; Max, S. 2004. A learning model of technology transfer for the kiwifruit industry, New Zealand Agricultural and Resource Economics Society Conference. NZARES, Lincoln.

Pascaul, J.V.; Bumatay, E.L. 2012. Farmers' experiences with the use of location-specific technologies in Cabanatuan City, nueva ecija, Philippines. Asia Life Sciences 21: 299-315.
Phillips, C.B.; McNeill, M.R.; Hardwick, S.; Vink, C.J.; Kean, J.M.; Bewsell, D.; Ferguson, C.M.; Winder, L.M.; Iline, I.I.; Barron, M.C.; Stuart, B. 2007. Clover root weevil in the South Island: Detection, response and current distribution. New Zealand Plant Protection 60: 209-216.

Röling, N. 2009. Pathways for impact: scientists' different perspectives on agricultural innovation. International Journal of Agricultural Sustainability 7: 83-94.

Schut, M.; Klerkx, L.; Rodenburg, J.; Kayeke, J.; Hinnou, L.C.; Raboanarielina, C.M.; Adegbola, P.Y.; van Ast, A.; Bastiaans, L. 2014a. RAAIS: Rapid Appraisal of Agricultural Innovation Systems (Part I): A diagnostic tool for integrated analysis of complex problems and innovation capacity. Agricultural Systems 132: 1-11.

Schut, M.; van Paassen, A.; Leeuwis, C.; Klerkx, L. 2014b. Towards dynamic research configurations: A framework for reflection on the contribution of research to policy and innovation processes. Science and Public Policy 41: 207-218.

Scott, J.M.; Gaden, C.A.; Edwards, C.; Paul, D.R.; Marchant, R.; Hoad, J.; Sutherland, H.; Coventry, T.; Dutton, P. 2013. Selection of experimental treatments, methods use and evolution of management guidelines for comparing and measuring three grazed farmlet systems. Animal Production Science 53: 628-642.

Sewell, A.M.; Gray, D.I.; Blair, H.T.; Kemp, P.D.; Kenyon, P.R.; Morris, S.T.; Wood, B.A. 2014. Hatching new ideas about herb pastures: Learning together in a community of New Zealand farmers and agricultural scientists. Agricultural Systems 125: 63-73.

Spielman, D.J.; Ekboir, J.; Davis, K. 2009. The art and science of innovation systems inquiry: Applications to Sub-Saharan African agriculture. Technology in Society 31: 399-405.

Vanclay, F. 2004. Social principles for agricultural extension to assist in the promotion of natural resource management. Australian Journal of Experimental Agriculture 44: 213-222. 